\title{
Origin of the low compressibility in hard nitride spinels
}

Mori-Sánchez, P.; Marqués, M.; Beltrán, A.; Jiang, Jianzhong; Gerward, Leif; Recio, J. M.

\section{Published in:}

Physical Review B Condensed Matter

Link to article, DOI:

10.1103/PhysRevB.68.064115

Publication date:

2003

Document Version

Publisher's PDF, also known as Version of record

Link back to DTU Orbit

Citation (APA):

Mori-Sánchez, P., Marqués, M., Beltrán, A., Jiang, J., Gerward, L., \& Recio, J. M. (2003). Origin of the low compressibility in hard nitride spinels. Physical Review B Condensed Matter, 68(6), 064115.

https://doi.org/10.1103/PhysRevB.68.064115

\section{General rights}

Copyright and moral rights for the publications made accessible in the public portal are retained by the authors and/or other copyright owners and it is a condition of accessing publications that users recognise and abide by the legal requirements associated with these rights.

- Users may download and print one copy of any publication from the public portal for the purpose of private study or research.

- You may not further distribute the material or use it for any profit-making activity or commercial gain

- You may freely distribute the URL identifying the publication in the public portal 


\title{
Origin of the low compressibility in hard nitride spinels
}

\author{
P. Mori-Sánchez, ${ }^{1, *}$ M. Marqués, ${ }^{2}$ A. Beltrán, ${ }^{3}$ J. Z. Jiang, ${ }^{4}$ L. Gerward ${ }^{4}$ and J. M. Recio ${ }^{2,}$ \\ ${ }^{1}$ Department of Chemistry, Duke University, Durham, North Carolina 27708-0354, USA \\ ${ }^{2}$ Departamento de Química Física y Analítica, Universidad de Oviedo, E-33006 Oviedo, Spain \\ ${ }^{3}$ Departament de Ciències Experimentals, Universitat Jaume I, E-12080 Castelló, Spain \\ ${ }^{4}$ Department of Physics, Technical University of Denmark, DK-2800 Lyngby, Denmark
}

(Received 1 April 2003; published 29 August 2003)

\begin{abstract}
A microscopic investigation of first-principles electron densities of $\gamma-\mathrm{A}_{3} \mathrm{~N}_{4}(\mathrm{~A}: \mathrm{C}, \mathrm{Si}, \mathrm{Ge})$ spinels reveals a clear relationship between the compressibility and the chemical bonding of these materials. Three striking findings emanate from this analysis: (i) the chemical graph is governed by a network of highly directional strong bonds with covalent character in $\gamma-\mathrm{C}_{3} \mathrm{~N}_{4}$ and different degrees of ionic polarization in $\gamma-\mathrm{Si}_{3} \mathrm{~N}_{4}$ and $\gamma-\mathrm{Ge}_{3} \mathrm{~N}_{4}$, (ii) nitrogen is the lowest compressible atom controlling the trend in the bulk modulus of the solids, and (iii) the group-IV counterions show strong site dependent compressibilities enhancing the difficulty in the synthesis of the spinel phases of these nitrides.
\end{abstract}

DOI: 10.1103/PhysRevB.68.064115

PACS number(s): 61.50.Lt, 61.50.Ah, 62.50.+p, 64.30.+t

\section{INTRODUCTION}

A great effort is currently being invested in the synthesis and characterization of the so-called intrinsic superhard materials exhibiting simultaneously very low compressibilities, wide thermodynamic ranges of chemical stability, and high decomposition temperatures. ${ }^{1}$ The search for these compounds is mainly guided by the empirical trends found in the pressure $(p)$ response of a variety of binary and ternary crystals. This systematic behavior has prompted the proposal of simple correlations involving coordination polyhedral volumes $^{2}$ or nearest-neighbor distances ${ }^{3,4}$ along with some bonding index as the key parameters to estimate bulk moduli $(B)$ of solids. In tetrahedrally bonded compounds, the success of Cohen's equation ${ }^{3}$ has fueled the investigation of carbon nitride polymorphs ${ }^{5-8}$ since it predicts $B$ values significantly larger than diamond. However, different energetic arguments rise reasonable doubts on the feasibility of the synthesis of low compressible hexagonal $\mathrm{C}_{3} \mathrm{~N}_{4}$ since a preference for $\mathrm{N}$-deficient or $\mathrm{C}$-rich compositions has been recognized. ${ }^{1,6,8}$

It is also well known that nitrides show a much more versatile response to hydrostatic pressure than oxides. For example, contrarily to the uniform behavior of general $\mathrm{AB}_{2} \mathrm{O}_{4}$ spinels with zero pressure bulk moduli $\left(B_{0}\right)$ clustering around $200 \mathrm{GPa}$, nitride spinels are predicted to have $B_{0}$ values ranging from 200 to $400 \mathrm{GPa}^{4}{ }^{4}$ Experimental and theoretical works have identified these cubic high-pressure polymorphs as a new class of potential superhard materials (see, for example, Refs. 4, 9-14, and references therein). The synthesis of these $\gamma-\mathrm{A}_{3} \mathrm{~N}_{4}(\mathrm{~A}: \mathrm{C}, \mathrm{Si}, \mathrm{Ge})$ phases reveals that the lower the compressibility the higher the difficulty to obtain the material. It is clear that the presence in the spinel structure of sixfold coordination enhances the packing efficiency leading to an increase of the bulk modulus in these binary nitrides. But, simultaneously, it introduces high energetic costs to promote atoms A into a $s p^{3} d^{2}$ hybridlike configuration provided directional $\mathrm{A}-\mathrm{N}$ bonds are formed in the crystal. This is a relevant question that deserves detailed examination. Up to date, only $\gamma-\mathrm{Ge}_{3} \mathrm{~N}_{4}$ and $\gamma-\mathrm{Si}_{3} \mathrm{~N}_{4}$ have been synthesized through careful experiments involving both high-pressure and high-temperature conditions, whereas $\gamma-\mathrm{C}_{3} \mathrm{~N}_{4}$ has not been found in the cubic phase. The behavior under pressure of these spinel structures shows similarities with the rutile polymorphs in the analogous $\mathrm{AO}_{2}$ family, where the presence of a sixfold coordinated $\mathrm{C}$ prevents again the high-pressure synthesis of a stishovitelike phase for $\mathrm{CO}_{2}$.

It seems, therefore, very convenient to undertake fundamental investigations aimed to provide physical support to the well-established correlations while paying special attention to the predictions of low compressible compounds. The understanding of the observed relation between incompressibility and difficulty to attain pure crystalline samples can benefit from the basic research of the bonding features in these materials. In this line, an accurate microscopic analysis of the electron density of the cubic polymorphs of $\mathrm{A}_{3} \mathrm{~N}_{4}$ crystals is proposed in this work to characterize the chemical bonding and to identify the atomic contributions to the macroscopic compressibility of these materials. Electron densities, unit cell geometries, and equations of state (EOS) are calculated up to $50 \mathrm{GPa}$ at static conditions (zero temperature and zero point vibrational contributions neglected) by means of first-principles techniques. The topology of the electron density is examined by means of Bader's atoms in molecules (AIM) formalism. ${ }^{15}$ Our study allows to discriminate the role played by $\mathrm{A}-\mathrm{N}$ bonds in the three crystals and their different strength at the fourfold and sixfold coordinations. Moreover, volumes and compressibilities can be rigorously associated to each of the non equivalent atoms of the unit cell. The atomic volumes and compressibilities are additive and recover the corresponding bulk values. ${ }^{17}$ This simple partition is also related here to the more usual decomposition in terms of the elementary $\mathrm{AN}_{4}$ and $\mathrm{AN}_{6}$ polyhedra of the cubic spinel structures. ${ }^{18}$ As a result, the linking between compressibility and chemical bonding is clearly established, and factors determining the difficulty in the synthesis of $\gamma-\mathrm{A}_{3} \mathrm{~N}_{4}$ polymorphs are also derived.

The rest of the paper is organized as follows: In Sec. II, the technical details are briefly given for the total energy calculations, the AIM analysis, and the compressibility de- 
composition. Section III contains the discussion of our results with the interpretation of the equations of state in terms of the elementary polyhedra and the chemical bonding. The last section summarizes the main findings of our investigation.

\section{COMPUTATIONAL ASPECTS}

Total energy ( $\left.E_{\text {crys }}\right)$ calculations based on the density functional theory were performed using the Becke ${ }^{19}$ and Perdew-Wang ${ }^{20}$ nonlocal exchange and correlation functionals, respectively, as implemented in the CRYSTAL package. ${ }^{21}$ Standard Gaussian-type basis sets of triple- $\zeta$ quality ${ }^{21}$ were used with the modification of the most diffuse exponents of nitrogen, carbon, silicon, and germanium that were optimized requiring $E_{\text {crys }}$ to be minimum at the corresponding experimental or theoretical equilibrium geometries of the $\gamma-\mathrm{A}_{3} \mathrm{~N}_{4}$ crystals. For $\gamma-\mathrm{C}_{3} \mathrm{~N}_{4}$, the $\mathrm{C}$ basis set was also reoptimized at different volumes of the computed configuration space. Details of the basis sets are available upon request.

The electron densities coming from the crystalline wavefunctions are investigated under the AIM framework. ${ }^{15}$ The unit cell volume $(V)$ of the three $\gamma-\mathrm{A}_{3} \mathrm{~N}_{4}$ spinels is divided into nonoverlapping atomic regions containing one nucleus and surrounded by surfaces where the local flux of the electron density gradient is nil. Appropriate integrations within these basins yield atomic volumes $\left(V_{i}\right)$ and charges $\left(\mathcal{Q}_{i}\right)$. First order saddle points of the electron density unequivocally determine the existence of bond paths between pairs of atoms. The chemical nature of these bonds is characterized by the values of the electron density $\left(\rho_{b}\right)$ and the Laplacian $\left(\nabla^{2} \rho_{b}\right)$ of the electron density at those points. ${ }^{15,16}$ Since the atomic volumes fill up the unit cell space, atomic compressibilities $\left(\kappa_{i}\right)$ can be defined to decompose the macroscopic compressibility $(\kappa)$ using the following expression: ${ }^{17}$

$$
\kappa=\frac{1}{B}=\sum_{i} f_{i} \kappa_{i}, f_{i}=\frac{n_{i} V_{i}}{V}, \quad \kappa_{i}=-\frac{1}{V_{i}} \frac{\partial V_{i}}{\partial p},
$$

where $i$ runs over the nonequivalent atoms in the unit cell, and $n_{i}$ is the number of equivalent atoms $i$ in the unit cell.

In $\gamma-\mathrm{A}_{3} \mathrm{~N}_{4}$ spinels, the group-IV element $\mathrm{A}$ is located either at octahedral $\left(\mathrm{A}^{o}\right)$ or at tetrahedral $\left(\mathrm{A}^{t}\right)$ sites of a distorted face centered cubic packing of nitrogens. $\mathrm{A}^{t}$ atoms form a diamondlike subarray, whereas $\mathrm{A}^{o}$ are distributed in one half of a face centered cubic lattice. Nitrogens are inside distorted tetrahedra of three $\mathrm{A}^{o}$ and one $\mathrm{A}^{t}$ atoms. $\mathrm{N}$ internal position $(u, u, u)$ has been accurately optimized by minimizing $E_{\text {crys }}$ at different volumes. Numerical and Vinet analytical $^{22}$ fittings to the resulting $E_{\text {crys }}$ versus $V$ curve were performed to obtain the EOS and the $u(p)$ relationship. Atomiclike EOS and $\mathrm{AN}_{4}$ and $\mathrm{AN}_{6}$ polyhedral EOS were then evaluated using $V(P)$ and $u(p)$ values, and the equations $V^{t}=8 V(u-1 / 8)^{3} / 3$ and $V^{o}=16 V(u-3 / 8)^{2} u / 3$ (see Refs. 18 and 23 for more details).

\section{RESULTS AND DISCUSSION}

The calculated zero pressure properties of the three spinels are compared in Table I with the available experi-
TABLE I. Cohesive properties of group-IV nitride spinels. Lengths in $\AA$, $B_{0}$ in GPa.

\begin{tabular}{lcccccc}
\hline \hline & \multicolumn{2}{c}{$\gamma-\mathrm{C}_{3} \mathrm{~N}_{4}$} & \multicolumn{2}{c}{$\gamma-\mathrm{Si}_{3} \mathrm{~N}_{4}$} & \multicolumn{2}{c}{$\gamma-\mathrm{Ge}_{3} \mathrm{~N}_{4}$} \\
\hline & Present & Other & Present & Other & Present & Other \\
$a$ & 6.841 & $6.8702^{\mathrm{a}}$ & 7.846 & $7.7734^{\mathrm{b}}$ & 8.304 & $8.213^{\mathrm{c}}$ \\
$u$ & 0.2562 & $0.2568^{\mathrm{a}}$ & 0.2576 & $0.2583^{\mathrm{b}}$ & 0.2580 & $0.2577^{\mathrm{c}}$ \\
$d_{\mathrm{A}^{\mathrm{t}} \mathrm{N}}$ & 1.555 & $1.568^{\mathrm{a}}$ & 1.802 & $1.795^{\mathrm{b}}$ & 1.913 & $1.888^{\mathrm{c}}$ \\
$d_{\mathrm{A}^{\mathrm{o}}-\mathrm{N}}$ & 1.667 & $1.672^{\mathrm{a}}$ & 1.924 & $1.881^{\mathrm{b}}$ & 2.012 & $1.992^{\mathrm{c}}$ \\
$B_{0}$ & 415 & $369^{\mathrm{a}}$ & 335 & $290^{\mathrm{d}}-317^{\mathrm{e}}$ & 231 & $296^{\mathrm{f}}$ \\
$B_{0}^{\prime}$ & 3.91 & $3.85^{\mathrm{a}}$ & 2.78 & $4.9^{\mathrm{d}}-2.3^{\mathrm{e}}$ & 4.48 & $4.0^{\mathrm{f}}$ \\
\hline \hline
\end{tabular}

${ }^{\mathrm{a} C}$ Calculated (Ref. 11).

${ }^{\mathrm{b}}$ Experiment (Ref. 24).

${ }^{\mathrm{c}}$ Experiment (Ref. 10).

${ }^{\mathrm{d}}$ Experiment (Ref. 25).

${ }^{\mathrm{e}}$ Experiment (Ref. 13).

${ }^{\mathrm{f}}$ Experiment (Ref. 26).

mental data for $\gamma-\mathrm{Si}_{3} \mathrm{~N}_{4}$ and $\gamma-\mathrm{Ge}_{3} \mathrm{~N}_{4}$ and the calculated values for $\gamma-\mathrm{C}_{3} \mathrm{~N}_{4}$. The agreement is good in terms of the unit cell geometry. The lattice parameter $a$ increases around $1.5 \AA$ from $\gamma-\mathrm{C}_{3} \mathrm{~N}_{4}$ to $\gamma-\mathrm{Ge}_{3} \mathrm{~N}_{4}$, a large change compared with the variations found in oxide spinels. In the rutile phases of $\mathrm{SiO}_{2}$ and $\mathrm{GeO}_{2}$, the increase of the molecular volume is predicted to be lower than $4 \%,{ }^{27}$ whereas for the equivalent binary nitrides is greater than $15 \%$. Notice also that as $u$ is lower than 0.2625 the A-N distances in the octahedra $\left(d_{\mathrm{A}^{\mathrm{o}} \mathrm{N}}\right)$ are greater than in the tetrahedra $\left(d_{\mathrm{A}^{\mathrm{t}-\mathrm{N}}}\right) .{ }^{28}$ Some differences appear with respect to previous values of the bulk modulus. In particular, we suspect that the experimental value $\left(B_{0}=296 \mathrm{GPa}\right)$ reported for $\gamma-\mathrm{Ge}_{3} \mathrm{~N}_{4}$ (Ref. 26) is too high. In fact, it is even higher than the $B_{0}$ $=290 \mathrm{GPa}$ value obtained by Zerr et al. ${ }^{25}$ in $\gamma-\mathrm{Si}_{3} \mathrm{~N}_{4}$. If the $B-V$ correlations hold for these materials, a much greater compressibility than in $\gamma-\mathrm{Si}_{3} \mathrm{~N}_{4}$ should be expected given the larger unit cell parameter of $\gamma-\mathrm{Ge}_{3} \mathrm{~N}_{4}$. Other calculations using the local density and gradient generalized approximations give $B_{0}$ values of $240 \mathrm{GPa}$ and $208 \mathrm{GPa}$, respectively. ${ }^{30}$ Concerning $\gamma-\mathrm{C}_{3} \mathrm{~N}_{4}$, Teter and Hemley also predicted $B_{0}$ above $400 \mathrm{GPa}$ for several $\mathrm{C}_{3} \mathrm{~N}_{4}$ polymorphs, ${ }^{5}$ in agreement with our results.

A key parameter to understand the crystal response to hydrostatic pressure in spinels is the slope of the $u(p)$ curve. We have found negative $d u / d p$ values around -1.5 $\times 10^{-5} \mathrm{GPa}^{-1}$ in $\gamma-\mathrm{C}_{3} \mathrm{~N}_{4}$ and $\gamma-\mathrm{Si}_{3} \mathrm{~N}_{4}$ and about -2.0 $\times 10^{-5}$ in $\gamma-\mathrm{Ge}_{3} \mathrm{~N}_{4} \mathrm{GPa}^{-1}$. This means that $u$ deviates more from the 0.2625 value as pressure is applied and, consequently, $d_{\mathrm{A}^{\mathrm{O}}-\mathrm{N}}$ decreases less than $d_{\mathrm{A}^{\mathrm{t}-\mathrm{N}}}$. These bond length compressibilities roughly determine the polyhedral compressibilities as illustrated by a higher $B_{i}$ value in the $\mathrm{AN}_{6}$ than in the $\mathrm{AN}_{4}$ polyhedra (see Table II). Our recent experiments in $\gamma-\mathrm{Si}_{3} \mathrm{~N}_{4}$ confirm this behavior. ${ }^{13}$ Moreover, they are in concordance with our previous analysis in several oxide spinels. ${ }^{18}$ Thus, the unit cell reduction under pressure is mostly achieved through $\mathrm{AN}_{4}$ deformations. A complete partition of the unit cell in terms of empty and occupied polyhedra reveals other two remarkable results: (i) the average of 
TABLE II. Calculated charges $\left(\mathcal{Q}_{i}\right.$ in $\left.e\right)$, volumes $\left(V_{i}\right.$ in bohr $\left.{ }^{3}\right)$, bulk moduli ( $B_{i}$ in GPa), and occupation factors $\left(f_{i}\right)$ in $\gamma-\mathrm{A}_{3} \mathrm{~N}_{4}$ spinels according to AIM and polyhedral analysis.

\begin{tabular}{lccccc}
\hline \hline Crystal & Constituent & $\mathcal{Q}_{i}$ & $V_{i}$ & $B_{i}$ & $f_{i}$ \\
\hline$\gamma-\mathrm{C}_{3} \mathrm{~N}_{4}$ & $\mathrm{C}^{t}$ & +0.85 & 35.5 & 111 & 0.1301 \\
$B_{0}=415$ & $\mathrm{C}^{o}$ & +0.83 & 28.0 & 346 & 0.2048 \\
& $\mathrm{~N}$ & -0.62 & 45.4 & 503 & 0.6651 \\
& $\mathrm{CN}_{4}$ & & 13.1 & 355 & 0.0482 \\
& $\mathrm{CN}_{6}$ & & 41.8 & 458 & 0.3084 \\
& & & & & \\
$\gamma-\mathrm{Si}_{3} \mathrm{~N}_{4}$ & $\mathrm{Si}^{t}$ & +2.97 & 29.5 & 91 & 0.0765 \\
$B_{0}=335$ & $\mathrm{Si}^{o}$ & +3.01 & 23.2 & 226 & 0.1206 \\
& $\mathrm{~N}$ & -2.25 & 82.9 & 395 & 0.8029 \\
& $\mathrm{SiN}_{4}$ & & 20.3 & 298 & 0.0497 \\
& $\mathrm{SiN}_{6}$ & & 61.7 & 361 & 0.3031 \\
$\gamma-\mathrm{Ge}_{3} \mathrm{~N}_{4}$ & & & & & \\
$B_{0}=231$ & $\mathrm{Ge}^{t}$ & +1.93 & 67.7 & 161 & 0.1402 \\
& $\mathrm{Ge}^{o}$ & +1.97 & 52.3 & 213 & 0.2165 \\
& $\mathrm{~N}^{o}$ & -1.47 & 77.6 & 262 & 0.6433 \\
& $\mathrm{GeN}_{4}$ & & 24.3 & 195 & 0.0502 \\
& $\mathrm{GeN}_{6}$ & & 72.8 & 260 & 0.3013 \\
\hline \hline
\end{tabular}

the tetrahedral and octahedral bulk moduli is found to be a good estimation of the macroscopic bulk modulus due to the low variation of $u$ with pressure in the three crystals, and (ii) those polyhedra with larger (smaller) volumes than in the ideal $u=0.25$ lattice show compressibilities larger (smaller) than the bulk value. ${ }^{29}$ This interesting rule is clearly obeyed by the $\mathrm{AN}_{4}$ and $\mathrm{AN}_{6}$ polyhedra as evidenced by the comparison of the occupation factors $\left(f_{i}\right)$ in the ideal unit cell $\left(\frac{1}{24}=0.0417\right.$ and $\frac{1}{3}=0.3333$, respectively) with the corresponding values in Table II. All these results indicate that the behavior of the group-IV nitride spinels resembles that of normal oxide ordered spinels with tetrahedra (octahedra) compressing more (less) than the bulk. ${ }^{18}$ This conduct is confirmed by the calculated atomic sizes of the group-IV element since the tetrahedral (octahedral) interstices are occupied by the biggest (smallest) A atom (see Table II).

Let us go now to the more distinctive findings enclosed in the electron density. A common feature of these nitride spinels is the existence of highly directional bonds governing the molecular graph and conferring them great resistance to pressure load. Nonetheless, the compressibility shows noticeable differences between the three compounds with a bulk modulus reduction of almost $185 \mathrm{GPa}$ along the sequence $\gamma-\mathrm{C}_{3} \mathrm{~N}_{4} \rightarrow \gamma-\mathrm{Si}_{3} \mathrm{~N}_{4} \rightarrow \gamma-\mathrm{Ge}_{3} \mathrm{~N}_{4}$. The nature of their respective chemical bonds (see Table III) explains the above trend. At zero pressure, it is observed that $\gamma-\mathrm{C}_{3} \mathrm{~N}_{4}$ shows strong covalent bonds with high values of the electron density and negative values of the Laplacian at the $\mathrm{C}-\mathrm{N}$ bond critical points. It is clearly shown in Fig. 1(a) that these bonds generate a three-dimensional network of charge accumulation $\left(\nabla^{2} \rho<0\right)$ very difficult to compress, as in C-diamond, for instance. The formation of directional covalent bonds implies the contribution of high angular momentum orbitals to the bonding in the octahedral environment.
TABLE III. The chemical bonding in $\gamma-\mathrm{A}_{3} \mathrm{~N}_{4}$ spinels according to the AIM analysis.

\begin{tabular}{lccc}
\hline \hline Crystal & Bond & $\rho_{b}\left(e / \mathrm{bohr}^{3}\right)$ & $\nabla^{2} \rho_{b}\left(e / \mathrm{bohr}^{5}\right)$ \\
\hline$\gamma-\mathrm{C}_{3} \mathrm{~N}_{4}$ & $\mathrm{C}^{t}-\mathrm{N}$ & 0.2227 & -0.4341 \\
$B_{0}=415 \mathrm{GPa}$ & $\mathrm{C}^{o}-\mathrm{N}$ & 0.1755 & -0.1826 \\
& & & \\
$\gamma-\mathrm{Si}_{3} \mathrm{~N}_{4}$ & $\mathrm{Si}^{t}-\mathrm{N}$ & 0.1160 & +0.3546 \\
$B_{0}=335 \mathrm{GPa}$ & $\mathrm{Si}^{o}-\mathrm{N}$ & 0.0941 & +0.2523 \\
& & & +0.1194 \\
$\gamma-\mathrm{Ge}_{3} \mathrm{~N}_{4}$ & $\mathrm{Ge}^{t}-\mathrm{N}$ & 0.1245 & +0.1275 \\
$B_{0}=231 \mathrm{GPa}$ & $\mathrm{Ge}^{o}-\mathrm{N}$ & 0.1018 & \\
\hline \hline
\end{tabular}

This is a critical requirement from an energetic perspective for the synthesis of $\gamma-\mathrm{C}_{3} \mathrm{~N}_{4}$. The $\mathrm{C}^{t}-\mathrm{N}$ bond is stronger than the $\mathrm{C}^{o}-\mathrm{N}$ one, in agreement with the bond orders calculated by Ching et al., ${ }^{4}$ and can be seen as a consequence of the shorter $\mathrm{C}-\mathrm{N}$ distance at the tetrahedral sites. There is no contradiction between the $\mathrm{C}-\mathrm{N}$ bond strengths and the values of the bulk moduli of $\mathrm{CN}_{4}$ and $\mathrm{CN}_{6}$ since the number of $\mathrm{C}-\mathrm{N}$ bonds involved in the polyhedra have also to be considered.

In $\gamma-\mathrm{Si}_{3} \mathrm{~N}_{4}$ and $\gamma-\mathrm{Ge}_{3} \mathrm{~N}_{4}$, the positive values of the Laplacian and the low values of the electron density at the bond points do not evidence a typical covalent bonding character. As displayed in Figs. 1(b) and 1(c), the isolaplacian lines of these two compounds show zones of charge accumulation within the nitrogen volumes, but now they are disrupted by the depletion of the electron density $\left(\nabla^{2} \rho>0\right)$ associated with $\mathrm{Si}$ and Ge. The main difference between $\gamma-\mathrm{Si}_{3} \mathrm{~N}_{4}$ and $\gamma-\mathrm{Ge}_{3} \mathrm{~N}_{4}$ lies in the greater ionicity of the former (see the ionic charges in Table II) with directional polarized bonds that tend to resemble the Laplacian map of $\gamma-\mathrm{C}_{3} \mathrm{~N}_{4}$. These characteristics inform of a departure from a central force description of the crystalline interactions and, consequently, the crystal does not verify Cauchy's relationships. The bonding in $\gamma-\mathrm{Ge}_{3} \mathrm{~N}_{4}$ is characterized by higher values of $\rho_{b}$ and lower values of $\nabla^{2} \rho_{b}$. Regions of flatter electron density surround the $\mathrm{Ge}-\mathrm{N}$ bonds which are now clearly less polarized. The deviation from Cauchy's elastic constant ratio $C_{44} / C_{12} \approx 1$ is then predicted to be lower than in $\gamma-\mathrm{Si}_{3} \mathrm{~N}_{4}$. The calculated values for this ratio by Soignard et al. ${ }^{31}$ are $1.78\left(\gamma-\mathrm{Si}_{3} \mathrm{~N}_{4}\right)$ and $1.42\left(\gamma-\mathrm{Ge}_{3} \mathrm{~N}_{4}\right)$, in a satisfactory agreement with our expectations.

The analysis of the topology of the electron density at selected pressures between 0 and $50 \mathrm{GPa}$ uncovers other interesting results. We have found that the size of nitrogen is greater than the corresponding sizes of the two non equivalent $\mathrm{A}$ atoms in each of the three spinels (see Table II). The greatest and smallest differences are found in $\gamma-\mathrm{Si}_{3} \mathrm{~N}_{4}$ and in $\gamma-\mathrm{C}_{3} \mathrm{~N}_{4}$ in concordance with the dominant ionic and covalent character of the two compounds, respectively. Given the stoichiometry of these nitrides, $\mathrm{N}$ becomes the atomic species determining the compressibility of the crystals, as Eq. (1) and the occupation factors inform. Contrarily to oxide materials, ${ }^{17} \mathrm{~N}$ atoms are surprisingly found to present the lowest compressibility in the three spinels with $B_{\mathrm{N}}$ values 
$(0,0,1)$

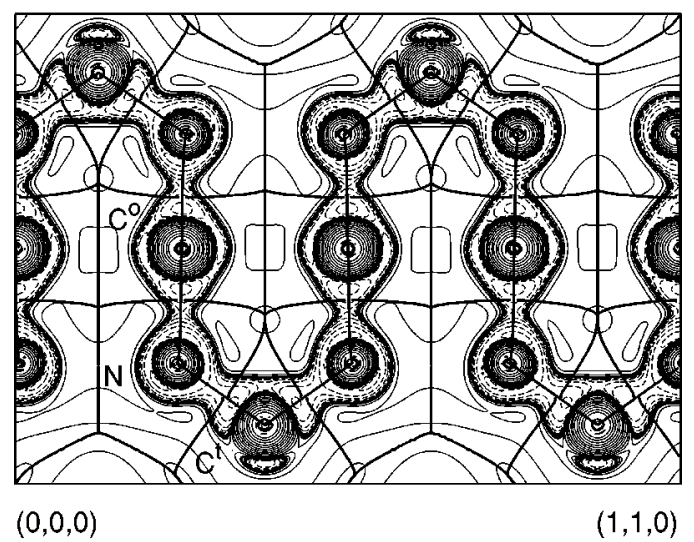

(a)

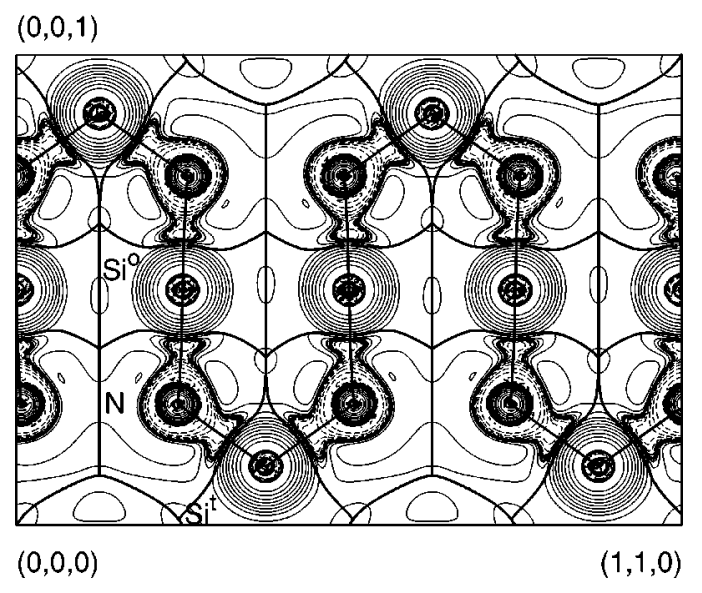

(b)

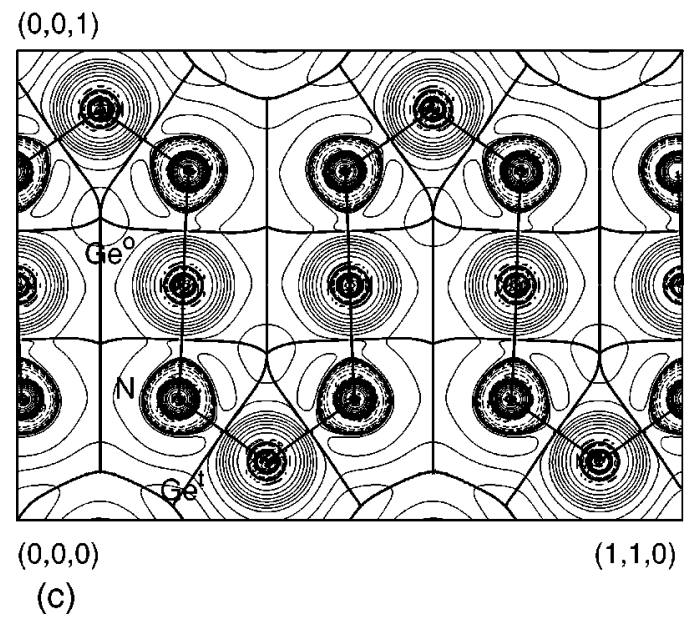

FIG. 1. $\nabla^{2} \rho$ isolines of $\gamma-\mathrm{C}_{3} \mathrm{~N}_{4}(\mathrm{a}), \gamma-\mathrm{Si}_{3} \mathrm{~N}_{4}(\mathrm{~b})$, and $\gamma-\mathrm{Ge}_{3} \mathrm{~N}_{4}$ (c) in the (110) plane at the equilibrium geometry. Dashed lines correspond to negative isovalues of charge accumulation. Nitrogen atoms do not exactly lie on this plane.

following the same trend as the $B_{0}$ crystal values. This fact is at the heart of the high hardness exhibited by these materials.

A successful explanation is given in terms of a simple physical argument. We define the average valence electron density $\rho_{\mathrm{av}, i}=N_{v, i} / V_{i}$ as a measure of the resistance of the atomic valence electron density to be compressed. $N_{v, i}$ is the effective number of valence electrons of atom $i$ in the crystal after considering $\mathcal{Q}_{i}$ values, i.e., $N_{v, i}=N_{v, i}^{0}-\mathcal{Q}_{i}$, where $N_{v, i}^{0}$ is the number of valence electrons in the atom. Core electrons are supposed to participate negligibly in the compressibility of the crystal. Atoms with greater values of $\rho_{\mathrm{av}, i}$ are expected to display lower compressibilities. The evaluation of $\rho_{\mathrm{av}, i}$ becomes satisfactory since it is obtained: (i) $\rho_{\mathrm{av}, N}$ $>\rho_{\mathrm{av}, A^{o}}>\rho_{\mathrm{av}, A^{t}}$, and (ii) $\rho_{\mathrm{av}, N}$ decreases from $\gamma-\mathrm{C}_{3} \mathrm{~N}_{4}$ to $\gamma-\mathrm{Ge}_{3} \mathrm{~N}_{4}$, i.e., these two sequences support the calculated $B_{i}$ trends.

On the other hand, the atomic volumes of the group-IV elements are greater in the tetrahedral than in the octahedral positions. This result is a consequence of the different confinement imposed by the four- and sixfold coordinations. $\mathrm{AN}_{4}$ and $\mathrm{AN}_{6}$ polyhedral volumes clearly show that whereas $\mathrm{A}^{o}$ atoms are constrained inside the octahedra, the electron density of the $\mathrm{A}^{t}$ atoms expands out of the corresponding tetrahedra. Thus, as pressure is applied it is much easier to reduce the atomic volume of $\mathrm{A}^{t}$ than $\mathrm{A}^{o}$, as illustrated by the different $B_{\mathrm{A}}$ values collected in Table II. The strong dependence of the cation compressibilities on their coordination correlates with the atomic number of the group-IV element. Thus, the difference between $B_{\mathrm{A}}^{o}$ and $B_{\mathrm{A}}^{t}$ is enhanced in $\gamma-\mathrm{C}_{3} \mathrm{~N}_{4}$. Our results clearly reveal that carbon atoms are required to behave in very different manners in the spinel structure according to their local environment. It seems very reasonable to add this observation to the factors explaining the difficulty in synthesizing the cubic spinel phase of $\mathrm{C}_{3} \mathrm{~N}_{4}$.

\section{CONCLUSIONS}

In summary, several physically based hints are put forward here to understand the observed behavior under pressure of spinel nitrides: (i) $\gamma-\mathrm{A}_{3} \mathrm{~N}_{4}$ polymorphs resemble normal ordered spinels, the average compressibility of $\mathrm{AN}_{6}$ and $\mathrm{AN}_{4}$ polyhedra being a good estimation of the compressibility of the crystals, (ii) the crystal bonding picture explains well the observed trend in the compressibility: strong covalent and highly polarized bonds dominate the chemical bonding of $\gamma-\mathrm{C}_{3} \mathrm{~N}_{4}$ and $\gamma-\mathrm{Si}_{3} \mathrm{~N}_{4}$, whereas weaker ionic interactions are present in $\gamma-\mathrm{Ge}_{3} \mathrm{~N}_{4}$, (iii) the low compressibility of $\mathrm{N}$ due to its high average electron density determines the superhard nature of these compounds, and (iv) the different volume and compressibility of the group-IV element in the fourfold and sixfold coordinations points towards procedures to reduce the mismatch (formation of defects by adding other elements or nanometer sized-grains) as a direction for the synthesis of superhard carbon nitrides.

\section{ACKNOWLEDGMENTS}

Financial support from the Spanish DGICYT (Project Nos. BQU2000-0466 and BQU2000-1425) and the Danish Technical Research Council are gratefully acknowledged. P.M.S. and M. M. thank the Fulbright Commission and the Spanish MCYT for a postdoctoral grant and a graduate grant, respectively. 
*Permanent address: Departamento de Química Física y Analítica, Universidad de Oviedo, E-33006 Oviedo, Spain.

†Author to whom correspondence should be addressed. Email address: mateo@ fluor.quimica.uniovi.es

${ }^{1}$ S. Veprek, J. Vac. Sci. Technol. A 17, 2401 (1999).

${ }^{2}$ R.M. Hazen and L.W. Finger, J. Geophys. Res. B 84, 6723 (1979).

${ }^{3}$ M.L. Cohen, Phys. Rev. B 32, 7988 (1985).

${ }^{4}$ W.Y. Ching, S. Mo, I. Tanaka, and M. Yoshiya, Phys. Rev. B 63, 064102 (2001).

${ }^{5}$ D.M. Teter and R.J. Hemley, Science 271, 53 (1996).

${ }^{6}$ F. Weich, J. Widany, and Th. Frauenheim, Phys. Rev. Lett. 78, 3326 (1997).

${ }^{7}$ J.E. Lowther, Phys. Rev. B 59, 11683 (1999).

${ }^{8}$ M. Mattesini and S.F. Matar, Phys. Rev. B 65, 075110 (2002).

${ }^{9}$ A. Zerr, G. Miehe, G. Serghiou, M. Schwarz, E. Kroke, R. Riedel, H. Fuess, P. Kroll, and R. Boehler, Nature (London) 400, 340 (1999).

${ }^{10}$ K. Leinenweber, M. O'Keefle, M. Somayazulu, H. Hubert, P.F. McMillan, and G.H. Wolf, Chem.-Eur. J. 5, 3076 (1999).

${ }^{11}$ S.D. Mo, L. Ouyang, W.Y. Ching, I. Tanaka, Y. Koyama, and R. Riedel, Phys. Rev. Lett. 83, 5046 (1999).

${ }^{12}$ T. Sekine, H. He, T. Kobayashi, M. Zhang, and F. Xu, Appl. Phys. Lett. 76, 3706 (2000).

${ }^{13}$ J.Z. Jiang, H. Lindelov, L. Gerward, K. Stähl, J.M. Recio, P. Mori-Sanchez, S. Carlson, M. Mezouar, E. Dooryhee, A. Fitch, and D.J. Frost, Phys. Rev. B 65, 161202(R) (2002).

${ }^{14}$ See the web page of the First International Workshop on Spinel Nitrides and Related Materials in http://www.hotmaterials.de

${ }^{15}$ R.F.W. Bader, Atoms in Molecules (Oxford University Press, Oxford, 1990).
${ }^{16}$ A. Martín Pendás and V. Luana, the CRITIC code, Universidad de Oviedo, 1995.

${ }^{17}$ A. Martín Pendás, A. Costales, M.A. Blanco, J.M. Recio, and V. Luaña, Phys. Rev. B 62, 13970 (2000).

${ }^{18}$ J.M. Recio, R. Franco, A. Martín Pendás, M.A. Blanco, R. Pandey, and L. Pueyo, Phys. Rev. B 63, 184101 (2001).

${ }^{19}$ A.D. Becke, Phys. Rev. A 38, 3098 (1988).

${ }^{20}$ J.P. Perdew, Electronic Structure of Solids '91, edited by P. Ziesche and H. Eschrig (Academic, Berlin, 1991).

${ }^{21}$ V.R. Saunders, R. Dovesi, C. Roetti, M. Causá, N.M. Harrison, R. Orlando, and C.M. Zicovich-Wilson, CRYSTAL98 User's Manual (University of Torino, Torino, 1998).

${ }^{22}$ P. Vinet, J. Ferrante, J.H. Rose, and J.R. Smith, J. Geophys. Res., [Solid Earth Planets] 92, 9319 (1987).

${ }^{23}$ P. Mori-Sánchez, R. Franco, A. Martín Pendás, V. Luaña, and J.M. Recio, Europhys. Lett. 54, 760 (2001).

${ }^{24}$ J.Z. Jiang, K. Stähl, R.W. Berg, D.J. Frost, T.J. Zhou, and P.X. Shi, Europhys. Lett. 51, 62 (2000).

${ }^{25}$ A. Zerr, M. Kempf, M. Schwarz, E. Kroke, M. Göken, and R. Riedel, J. Am. Ceram. Soc. 85, 86 (2002).

${ }^{26}$ M.S. Somayazulu, K. Leinenweber, H. Hubert, P.F. McMillan, and G.H. Wolf, Proc. AIRAPT-17 (1999).

${ }^{27}$ D.M. Christie and J.R. Chelikowsky, Phys. Rev. B 62, 14703 (2000).

${ }^{28}$ R.J. Hill, J.R. Craig, and G.V. Gibbs, Phys. Chem. Miner. 4, 317 (1979).

${ }^{29}$ L. Gracia, A. Beltrán, J. Andrés, R. Franco, and J.M. Recio, Phys. Rev. B 66, 224114 (2002).

${ }^{30}$ J. Dong, O.F. Sankey, S.K. Deb, G. Wolf, and P.F. McMillan, Phys. Rev. B 61, 11979 (2000).

${ }^{31}$ E. Soignard, M. Somayazulu, J. Dong, O.F. Sankey, and P.F. McMillan, J. Phys.: Condens. Matter 13, 557 (2001). 